\title{
Survivability of boar sperm stored under room temperature in extenders containing some natural products
}

\author{
Alafuro Akandi' \\ Simeon Ogochukwu Ugwu' \\ Ndubuisi Samuel Machebe ${ }^{1,2}$ \\ 'Department of Animal Science, \\ University of Nigeria, Nsukka, Nigeria; \\ 'Laboratory of Animal Reproduction, \\ College of Agriculture, Kinki \\ University, Nara, Japan
}

This article was published in the following Dove Press journal:

Open Access Animal Physiology

28 April 2015

Number of times this article has been viewed

Background: Semen extenders are used to create multiple insemination doses from a single ejaculate and contain buffers and nutrients suitable for storage of spermatozoa. The purpose of this study was to evaluate the survivability of boar sperm stored under room temperature in different extenders containing some natural products.

Methods: A volume of $10 \mathrm{~mL}$ of pooled semen collected from four mature crossbred (Landrace $\times$ Large White) boars was stored in 12 different extenders containing 1.0\%, 1.5\%, and $2.0 \%$ per liter each of honey, sugarcane juice, tomato juice, and pineapple juice. The semen samples were observed under a microscope every hour to determine sperm motility by scoring. Survivability of the sperm cells was taken as the average percentage number of motile spermatozoa in each extender recorded during 24 hour storage duration. The experimental layout was a $4 \times 3$ factorial in a randomized complete block design.

Results: Average sperm survivability was higher for semen stored in honey and sugarcane juice extenders compared $(P<0.05)$ to sperm stored in tomato and pineapple extenders. The proportion of spermatozoa that survived within the 24 hour storage time was highest in the honey group and lowest in the pineapple group. The average percentage of sperm that were motile was higher when $1.5 \%$ and $2.0 \%$ of test ingredients was included in extender compared $(P<0.01)$ to $1.0 \%$ inclusion rate.

Conclusion: The present study clearly demonstrates that spermatozoa can be stored in extenders containing honey, sugarcane juice, tomato juice, and pineapple juice. Moreover, the survivability of sperm in these extenders can be enhanced when the percentage constituent of these natural materials in the extenders is increased from $1.0 \%$ to $2.0 \%$ inclusion rates.

Keywords: semen extender, honey, sugarcane, tomato, pineapple

\section{Introduction}

The modern day farm animal reproduction is hinged on better reproductive techniques, one of which is artificial insemination (AI). The development of the AI technique in pig production has been mostly prompted by the dissemination of genes from improved boar and the fact that results are equivalent or even better than those related to natural service. ${ }^{1} \mathrm{AI}$ is an effective and globally accepted method of breeding animals including pigs. Its application is widely based on stored semen for future use. Pig producers have adapted the AI technology to their specific needs, by collecting semen and inseminating females on their own farms, which is frequently referred to as do-it-yourself AI. ${ }^{2}$

Semen collected from boars is ultimately diluted in any one of a variety of commercially available boar semen extenders. Among the commercially available boar semen extenders are Beltsville TS, Androhep ${ }^{+}$, Mulberry III, Acromax, X-CELL, 
Seminark, Vitasem LD, etc, ${ }^{3-6}$ and most of them are either short- or long-term preservation media. These extenders are used to create multiple insemination doses from a single ejaculate and contain buffers and nutrients, which provide spermatozoa a congenial environment that maintains their preservation capabilities and viability for 3 or more days postcollection. ${ }^{7}$ Some of the protective compounds added to extenders include antibiotics, albumin, bovine serum, ${ }^{1,2}$ and recently, whey protein. ${ }^{6}$ The addition of antibiotics to semen extenders is a common feature in commercial extenders, usually aimed at avoiding bacteria growth in extended semen. ${ }^{4}$ The addition of antibiotics as component of semen extenders may be justified because bacteria in semen are harmful to the quality of semen. Endotoxins produced by these bacteria interfere with spermatozoa survival time in semen and cause sperm agglutination and reduced motility. ${ }^{8,9}$ However, the use of antibiotics in human medicine and animal production, whether additive or therapeutic, has drawn international concern due to high occurrence of antibioticresistant bacteria strains. ${ }^{10}$ Measures to outright ban antibiotic use have already been taken by EU countries, limiting its use in animal production. Current knowledge about the possible later effect of antibiotics added to semen extenders on vitality of spermatozoa and the capability to fertilize the egg is yet to be clarified, and how they affect the acrosome structure of stored semen has not yet been determined. To avoid these likely complications, there is need to devise other means of decontamination of boar semen during preservation. A possible way is through the use of natural products that have antimicrobial effect against bacteria, fungi, and viruses. Knowledge regarding the possibilities for the use of natural substances for decontamination of boar sperm is low. ${ }^{10}$ Some natural products that have been added to boar semen are used basically as antioxidant to reduce lipid peroxidation although some may have an antimicrobial protective role. Some natural products have been used as components of semen extenders due to their high content of polyphenol, flavonoid, vitamins and minerals, etc and include green tea extracts, vitamins $\mathrm{C}$ and E, lycopene, etc. ${ }^{10-14}$ These and other yet to be identified natural products may conveniently replace antibiotics in semen preservation media once critically examined and tested by researchers.

Although several attempts have been made to extend the time of semen storage beyond 3 days (long-term preservation) without reducing fertility, ${ }^{7,15}$ the results have been inconsistent, and the price of long-term extenders when compared to short-term extenders is considered to be relatively high. ${ }^{16}$ Moreover, most of the available commercial extenders are stored at temperatures ranging from $16^{\circ} \mathrm{C}$ to $18^{\circ} \mathrm{C}$ for effective preservation of boar semen. ${ }^{3,4,6}$ Maintaining this storage temperature may be challenging in most developing countries, where little or no financial support is channeled to provision of research facilities and standard laboratories with functional refrigerators for storage, incubators, etc. Moreover, electricity in many rural communities where most pig farms are located is either nonexistent or inadequate. These challenges highlight the dire need to search for alternative long-term semen preservation media or extenders that are easy to make, stored at room temperature, and readily available at a lower cost. Taken together, this experiment was designed to develop simple extenders using available natural products that may have the capacity to preserve semen under room temperature condition. A careful development of semen diluents using available naturally based ingredients, which are less expensive and suitable for the breeding programs and needs of pig farmers worldwide, is indispensable in increasing the efficacy of reproduction in different pig breeds.

\section{Materials and methods Management of experimental animals and semen collection}

The study was conducted at the piggery unit of the Department of Animal Science Teaching and Research farm, University of Nigeria, Nsukka. Four mature crossbred (Landrace $\times$ Large White) boars aged 12 months and weighing an average of $57 \pm 1.3 \mathrm{~kg}$ were used in the study. The boars were housed in open-sided, fly-proof pens measuring $3.2 \times 2.75 \mathrm{~m}$ with concrete feeding troughs and drinkers. Feeding was performed twice daily ( 8 am and $4 \mathrm{pm}$ ), with each boar receiving $2 \mathrm{~kg}$ of feed as ration. The feed was $16 \%$ crude protein and $3,000 \mathrm{Kcal} / \mathrm{kg}$ metabolizable energy diet composed of cassava meal, wheat offals, spent grain, bambara waste, palm kernel cake, common salt, lysine, and vitamin and mineral premix. Clean drinking water was provided daily.

\section{Experimental layout}

The experimental layout was a $4 \times 3$ factorial arrangement of treatment in a randomized complete block design with the type of natural product, namely honey, sugarcane juice, tomato juice, and pineapple juice, as factor $\mathrm{A}$ and percentage of natural product per liter $(\mathrm{L})$ of extender $(1.0 \%, 1.5 \%$, and $2.0 \%$ ) as block B. These combinations were used to formulate 12 different semen extenders. The compositions of the different extenders per L are shown in Table 1. An antibiotic was intentionally omitted as component of the extenders to ascertain the antimicrobial potentials of the test ingredients. 
Table I Composition of the different extending medium/diluents per liter

\begin{tabular}{|c|c|c|c|c|c|c|c|c|c|c|c|c|}
\hline Ingredients & HE-I & HE-2 & HE-3 & PE-I & PE-2 & PE-3 & SE-I & SE-2 & SE-3 & TE-I & TE-2 & TE-3 \\
\hline \multicolumn{13}{|c|}{ Amount contained in $1,000 \mathrm{~mL}$ of $\mathrm{DW}$} \\
\hline Honey $(\mathrm{mL})$ & 20.0 & 15.0 & 10.0 & & & & & & & & & \\
\hline Pineapple juice (mL) & & & & 20.0 & 15.0 & 10.0 & & & & & & \\
\hline Sugarcane juice $(\mathrm{mL})$ & & & & & & & 20.0 & 15.0 & 10.0 & & & \\
\hline Tomato juice (mL) & & & & & & & & & & 20.0 & 15.0 & 10.0 \\
\hline Glucose $(\mathrm{g})$ & 2.0 & 2.0 & 2.0 & 2.0 & 2.0 & 2.0 & 2.0 & 2.0 & 2.0 & 2.0 & 2.0 & 2.0 \\
\hline Sodium bicarbonate $(\mathrm{g})$ & 1.2 & 1.2 & 1.2 & 1.2 & 1.2 & 1.2 & 1.2 & 1.2 & 1.2 & 1.2 & 1.2 & 1.2 \\
\hline Sodium citrate $(\mathrm{g})$ & 3.6 & 3.6 & 3.6 & 3.6 & 3.6 & 3.6 & 3.6 & 3.6 & 3.6 & 3.6 & 3.6 & 3.6 \\
\hline EDTA & 2.0 & 2.0 & 2.0 & 2.0 & 2.0 & 2.0 & 2.0 & 2.0 & 2.0 & 2.0 & 2.0 & 2.0 \\
\hline $\mathrm{pH}$ & 10.6 & 10.5 & 10.6 & 10.7 & 10.9 & 10.9 & 10.5 & 10.5 & 10.5 & 10.6 & 10.5 & 10.5 \\
\hline
\end{tabular}

Note: I, 2, and 3, represents extender having $1.0 \%$, $1.5 \%$, or $2.0 \%$ inclusion amounts, respectively.

Abbreviations: DW, distilled water; EDTA, ethylenediaminetetraacetic acid; HE, honey extender; PE, pineapple extender; SE, sugarcane extender; TE, tomato extender.

Fresh natural products (honey, sugarcane, pineapple, and tomato) used in this research were purchased from local fruit suppliers in Nsukka Main Market, Enugu State. The fruit was washed thoroughly in water, chopped into pieces, and blended for about 5 minutes using a juicer. The processed juices were stored in $250 \mathrm{~mL}$ bottles and used immediately for the experiment. The honey was used as purchased without further processing.

Forty-eight ejaculates were obtained from four normal and sexually mature Large White $\times$ Landrace crossbred boars using the dummy and artificial vagina at twice weekly intervals between 8 am and 10 am for 6 weeks duration. Ejaculates were visually separated into sperm-rich and sperm-poor fractions, but only the sperm-rich fractions used in storage experiments were assessed for volume, progressive motility, sperm concentration, and live spermatozoa using standard laboratory methods. Portions of sperm-rich fraction were diluted to a high concentration of $10 \times 10^{6}$ based on number of motile sperm in the fraction to facilitate easy microscopic examination. ${ }^{17}$

On each day of semen collection, $10 \mathrm{~mL}$ of pooled semen were diluted (1:4) in each of the constituted extenders. Semen samples from the four boars were pooled to reduce any likely variation in semen quality that may be caused by individual differences in genetic blueprint of the boars. Portions of diluted semen $(5 \mathrm{~mL})$ were stored in $10 \mathrm{~mL}$ glass tubes with a plastic cork at room temperature of $25^{\circ} \mathrm{C}$ for 24 hours. Hourly motility scores assessed by estimation of percentage of sperm cells with progressive forward motility were used to determine sperm survivability in extenders during storage. Briefly, a $5 \mu \mathrm{L}$ drop of diluted semen was examined for number of sperm with normal forward progressive movement in a visual field of phase contrast microscopy with a heating stage $\left(38^{\circ} \mathrm{C}\right)$ at $100 \times$ magnification. At least 100 sperm were examined during each motility assessment, and each sample was examined at three different microscopic fields. Duplicate counts were done, and the average value recorded as percentage motility. Motility was expressed as percentage of sperm showing normal forward progressive movements. ${ }^{18}$ Motility assessment was made by the same person to minimize differences during interpretation. Motility scores taken immediately after dilution were regarded as score for 0 hour storage, while experimental motility scores were recorded from 1-24 hours of storage. Twelve storage trials were conducted for each extender.

\section{Statistical analysis}

Data were analyzed according to the general linear procedure, with interaction in a randomized complete block design using SPSS statistical analytical package, version 8 (SPSS Inc., Chicago, IL, USA). The four natural products, honey, tomato, sugarcane, and pineapple juices, were the main factors, whereas the percentage amount of inclusion $(1.0 \%, 1.5 \%$, and $2.0 \%$ ) were the block variables. Preliminary analysis of data across weeks showed no significant differences with the weeks as treatment; hence, data was pooled and used for one analysis. The statistical model used was

$$
\mathrm{X}_{\mathrm{ijk}}=\mathrm{U}+\mathrm{A}_{\mathrm{i}}+\mathrm{S}_{\mathrm{j}}+(\mathrm{AS})_{\mathrm{ij}}+\mathrm{e}_{\mathrm{ijk}}
$$

where $X_{\mathrm{ijk}}$ is observed population, $U$ is population mean, $A_{i}$ is effect due to different natural products, $S_{j}$ is block effect (level of inclusion, \%), (AS) $)_{\mathrm{ij}}$ is interaction effects between $\mathrm{A}_{\mathrm{i}}$ and $\mathrm{S}_{\mathrm{j}}$, and $\mathrm{e}_{\mathrm{ijk}}$ is random experimental error. Treatment means that were significant were separated using Duncan options as found in the software package.

\section{Results}

Quality evaluation of pooled semen of boars showed that semen used in the study were of good quality. The average ejaculate volume was $142.5 \pm 4.74 \mathrm{~mL}$. The volume of gel 
and strained fractions of ejaculates were $18.33 \pm 0.14 \mathrm{~mL}$ and $124.10 \pm 2.18 \mathrm{~mL}$, respectively. The average progressive sperm motility, sperm concentration, and percentage of live sperm in ejaculates were $82.50 \% \pm 0.86 \%, 131.20 \pm 1.09\left(\times 10^{6} / \mathrm{mL}\right)$, and $86.50 \% \pm 1.84 \%$, respectively. The survivability of sperm (determined as a measure of the mean hourly percentage of motile spermatozoa) stored in the different extenders under room temperature for 24 hours is shown in Table 2. The average percentage survivability of sperm stored in honey, sugarcane, tomato, and pineapple extenders was 60.89 \pm 2.55 , $59.10 \pm 2.01,57.99 \pm 1.97$, and 51.59 \pm 1.95 , respectively. There was distinct variation $(P<0.05)$ in the survival of spermatozoa in the extenders. The proportion of spermatozoa that survived within the 24 hours of storage time was highest in the honey group and lowest in the pineapple group. Although the proportion of sperm that survived in the sugarcane group was similar to honey and tomato groups, it differed $(P<0.05)$ from the percentage of sperm that survived in pineapple groups $(59 \%$ versus $52 \%$ ). The percentage of sperm that survived increased as the percentage of the test ingredients (honey, sugarcane, tomato, pineapple) in each extender was increased from $1.0 \%$ to $2.0 \%$. The average percentage of sperm that were motile was higher when $1.5 \%$ and $2.0 \%$ of test ingredients were included in extender compared $(P<0.01)$ to $1.0 \%$ inclusion rate (Figure 1). Collectively, no significant $(P>0.05)$ interaction (extender by inclusion rate) was witnessed in average motility of sperm during storage (Table 3 ). However, considering each test ingredient and percentage inclusion rate, the survivability of spermatozoa stored in pineapple juice extender was generally lower than that of other groups (Figure 1). In addition, average survival time of spermatozoa in extenders was longer for those stored in sugarcane compared to others (Figure 2). Average survival time for sperm cells extended in pineapple was less than 10 hours at room temperature while average survival time for sperm stored in sugarcane juice was

Table 2 Sperm motility (\%) of boar spermatozoa stored in different extenders under room temperature conditions (mean \pm SEM)

\begin{tabular}{|c|c|c|c|c|}
\hline \multicolumn{5}{|c|}{ Types of extenders } \\
\hline Honey & Sugarcane & Tomato & Pineapple & Probability \\
\hline \multirow{4}{*}{$60.89 \pm 2.55^{\mathrm{a}}$} & $59.10 \pm\left. 2.0\right|^{a, b}$ & $57.99 \pm 1.97^{b}$ & $51.59 \pm 1.95^{\mathrm{c}}$ & $P=0.02$ \\
\hline & \multicolumn{4}{|c|}{ Inclusion levels of products } \\
\hline & $1.0 \%$ & $1.5 \%$ & $2.0 \%$ & \\
\hline & $52.49 \pm 1.93^{b}$ & $58.16 \pm 1.98^{a}$ & $60.47 \pm 1.65^{a}$ & $P=0.01$ \\
\hline
\end{tabular}

Note: ${ }^{a-c}$ Means in the same row with different superscript are significant $(P<0.05)$. Abbreviation: SEM, standard error of the mean.
11.5 hours. Generally, when all the natural ingredients were considered and the average percentage motility of sperm in these extenders over time in hours was plotted (Figure 3), a decrease in sperm motility for all the extenders was observed. Sperm from semen stored in sugarcane remained alive for about 23 hours storage, whereas sperm stored in pineapple lived for 20 hours (Figure 3).

\section{Discussion}

The present study clearly demonstrates that spermatozoa can be stored in extenders containing honey, sugarcane juice, tomato juice, and pineapple juice. Moreover, the survivability of sperm in these extenders can be enhanced when the percentage constituent of these materials in the extenders is increased from $1.0 \%$ to $2.0 \%$ inclusion rates. In addition, the quality of semen produced by the crossbred boars and used in this study was consistent with previous ${ }^{19}$ and recent ${ }^{20}$ reports of the quality of semen produced by crossbred boars in the tropics.

Different types of macromolecules added as component of sperm extending media may affect the survivability of sperm during storage. Since other components of the extenders were similar, excluding the experimental materials (honey, sugarcane, tomato, and pineapple juices), it shows that the effect observed in the lifespan of the sperm during short-term storage ( 24 hours) at room temperature may have been caused by changes in the micro and macroenvironment of sperm storage medium caused by variation in the component of natural materials added to the storage medium. Generally, sperm motility decreased with longer duration of storage in agreement with Lustyková et al. ${ }^{18}$ In our previous study, we showed that energy is very crucial for the maintenance of sperm motility and viability. ${ }^{21}$ Thus, it is expected that an adequate amount of energy is required by sperm during storage to maintain movement and other physiological functions. Hence, energy substrate like sugars in the storage media forms the source of materials for production of energy for motility. These materials are often depleted as the length of sperm storage is prolonged, leading to a decline in sperm motility. Average motility of sperm during storage in honey extender was higher than that of other treatments, with exception of sugarcane. Honey is one of the natural products from honey bee (Apis mellifera), and its composition has a multifactorial function. It contains approximately $80 \%(\mathrm{w} / \mathrm{v})$ of sugars (glucose, fructose, sucrose, and maltose) and has a potent in vitro activity against bacteria. ${ }^{22,23}$ It is known that honey contains antimicrobial peptide bee defensin-1 and high 


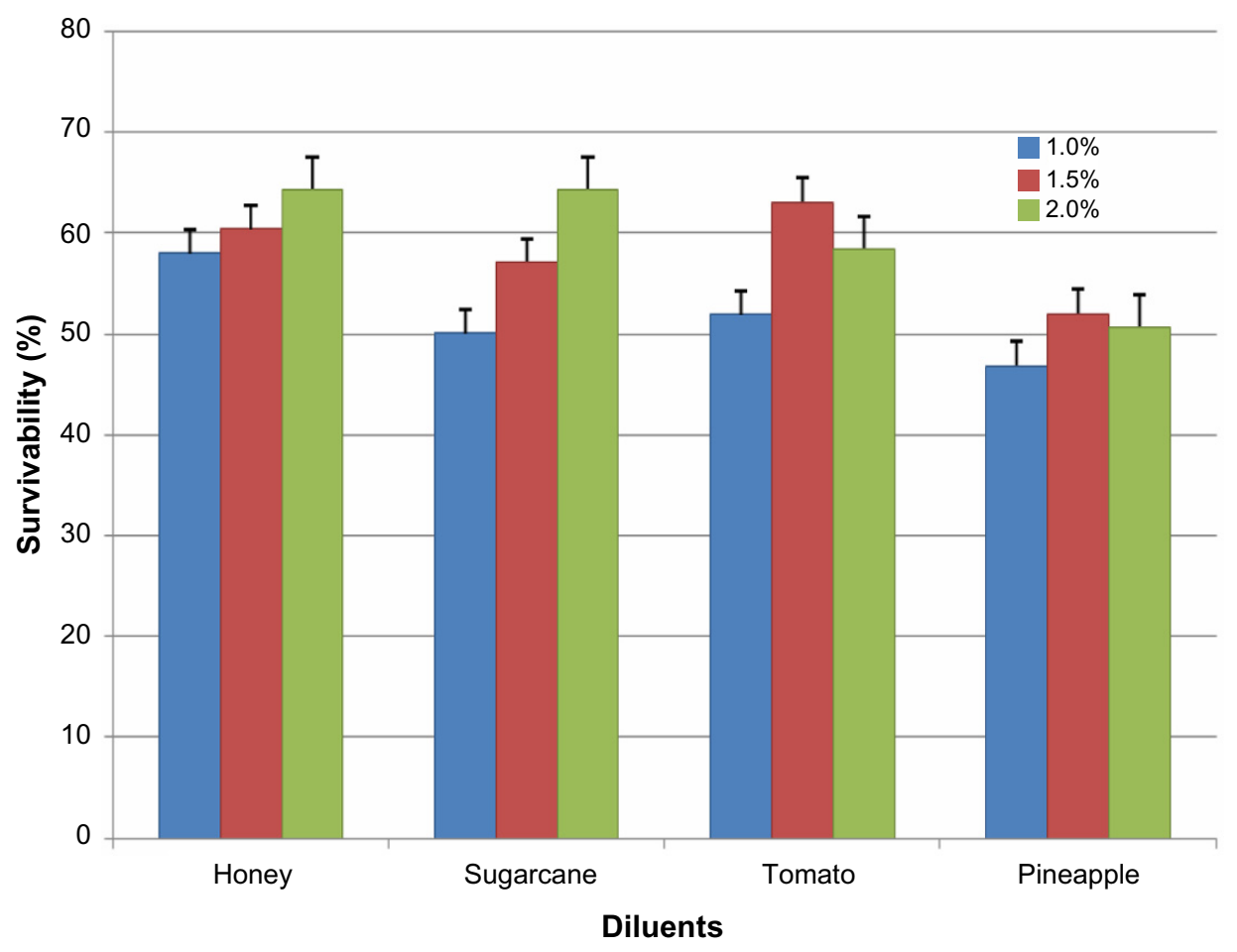

Figure I Mean percentage survivability of spermatozoa in difference extenders over 24 hour storage duration.

concentrations of methylglyoxal and hydrogen peroxide on dilution in water. ${ }^{23}$ The authors also reported that the dilution of honey up to $30 \%$ formed the maximum amount of hydrogen peroxide in media. These inherent properties of honey are responsible for its high antimicrobial properties and, in addition to the presence of sugars, may have contributed to the maintenance of high motility of sperm cells over time when stored in honey extenders. The availability of these compounds could have increased the bacterial killing properties of honey extending media thereby reducing the contest for available substrate by sperm and bacteria, hence the greater survivability of sperm in the medium. In a similar manner, sperm survivability when stored in sugarcane juice extenders was intermediate when compared to that of honey and tomato extenders. However, the life span of sperm cells

Table 3 Effect of interaction of types of extenders by level of inclusion of sperm motility during storage (mean \pm SEM)

\begin{tabular}{llllll}
\hline \multicolumn{5}{c}{ Types of extenders } \\
\cline { 2 - 6 } Honey & Sugarcane & Tomato & Pineapple & Probability \\
\hline Inclusion levels of products \\
$1.0 \%$ & $58.05 \pm 4.84$ & $50.10 \pm 3.31$ & $51.90 \pm 3.44$ & $49.32 \pm 3.38$ & \\
$1.5 \%$ & $60.38 \pm 4.56$ & $57.14 \pm 4.10$ & $63.05 \pm 3.35$ & $52.00 \pm 3.57$ & $0.06 \mathrm{NS}$ \\
$2.0 \%$ & $64.38 \pm 3.76$ & $64.40 \pm 2.50$ & $59.08 \pm 3.29$ & $53.42 \pm 3.25$ & \\
\hline
\end{tabular}

Abbreviations: NS, no significant interaction effect $(P>0.05)$; SEM, standard error of the mean. in sugarcane extenders lasted for about 2.2 hours more than the others (Figure 3), thus suggesting high availability of energy substrates for maintenance of life of the sperm cells. Sugarcane juice contains about $84 \%$ to $90 \%$ (\% dry matter) of total sugars, mainly sucrose, fructose, glucose, and other phenolic compounds and flavonoid, which also has an antimicrobial effect. ${ }^{24,25}$ These properties in addition to its slightly acidic nature could have been adequate for the continued existence of sperm cells in the extending medium compared to sperm cells stored in tomato and pineapple medium. Some properties in tomato and pineapple juices may not have been adequate for survival of sperm cells in the extenders.

To the best of our knowledge, there seems to be a dearth of information on the use of these natural materials, honey, sugarcane juice, tomato juice, and pineapple juice, as components of semen extenders for boar sperm storage. In the literature, natural products like green tea extracts, Vitamins C and $\mathrm{E}$, lycopene, etc ${ }^{10-14}$ have been used for diluting rooster and canine semen, and these products have been found to be rich in polyphenols, flavonoids, and other essential vitamins and minerals that are thought to contribute to survivability of sperm during storage. ${ }^{14}$ Other reports have concentrated on the impact of commercially available boar sperm extenders on sperm survivability during short- and long-term storage. In spite 


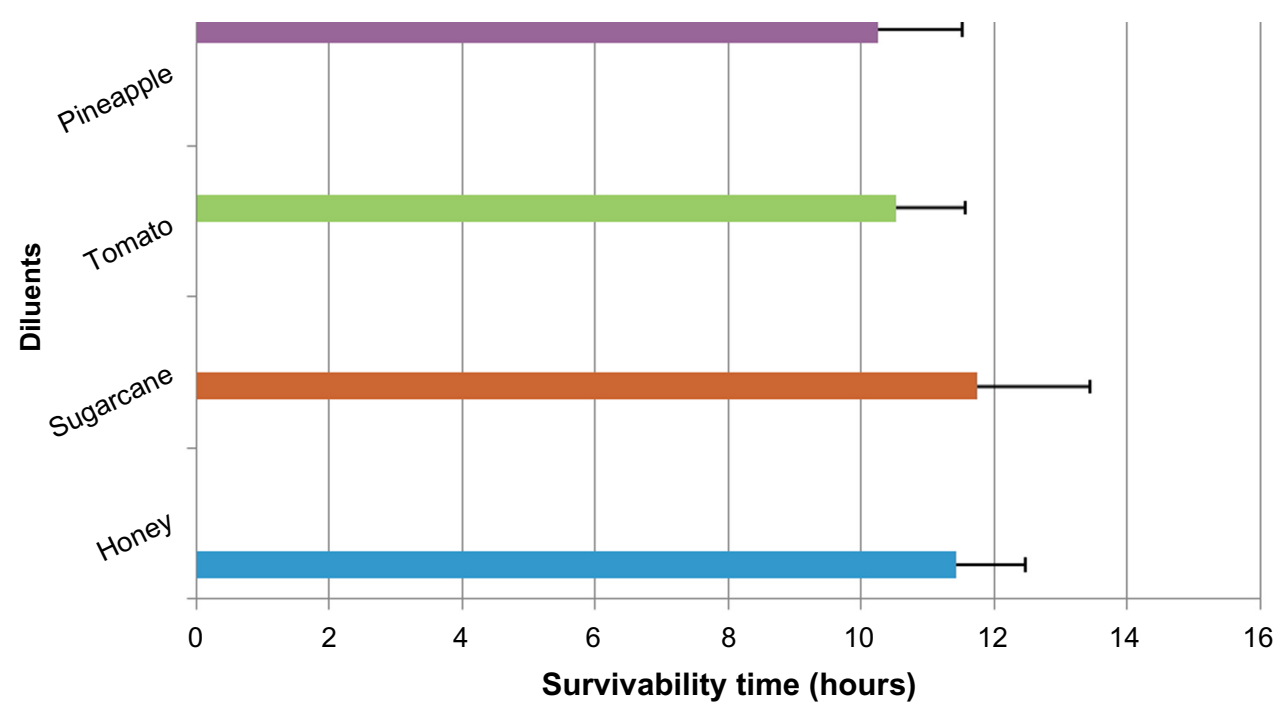

Figure 2 Survival time of sperm extenders.

of the reports of in vitro studies indicating no differences in cell variability between short- and long-term extenders, ${ }^{26,27}$ in vivo studies have shown degrees of variation among these commercial extenders. However, these differences were linked to factors not related to the extenders, namely differences in the design of the experiments, semen doses between first and second insemination, and number of inseminations. ${ }^{26}$ On the other hand, using boars and humans, possible effects of different constituents of commercial extenders of sperm integrity during storage have been indicated. ${ }^{27,28}$ The authors of these studies noted that the constituents of different commercial extenders impact on the membrane quality of boar sperm and reduce the fertilizing capacity of sperm cells at storage in humans. ${ }^{27,28}$ Such changes probably result from ageing of spermatozoa, lipid peroxidation, and other related factors. ${ }^{2,29}$ Lipids are one of the main components of sperm membrane, which provide them with energy, participate in numerous biochemical processes, and play an important role in sperm function. The high concentration of polyunsaturated fatty acids within sperm membrane determines peroxidative susceptibility of spermatozoa. ${ }^{29,30}$ Boar sperm seems to be especially sensitive to peroxidative damage due to the relatively high content of unsaturated fatty acids in the sperm membrane, and peroxidation of lipids exposed to oxygen is responsible for

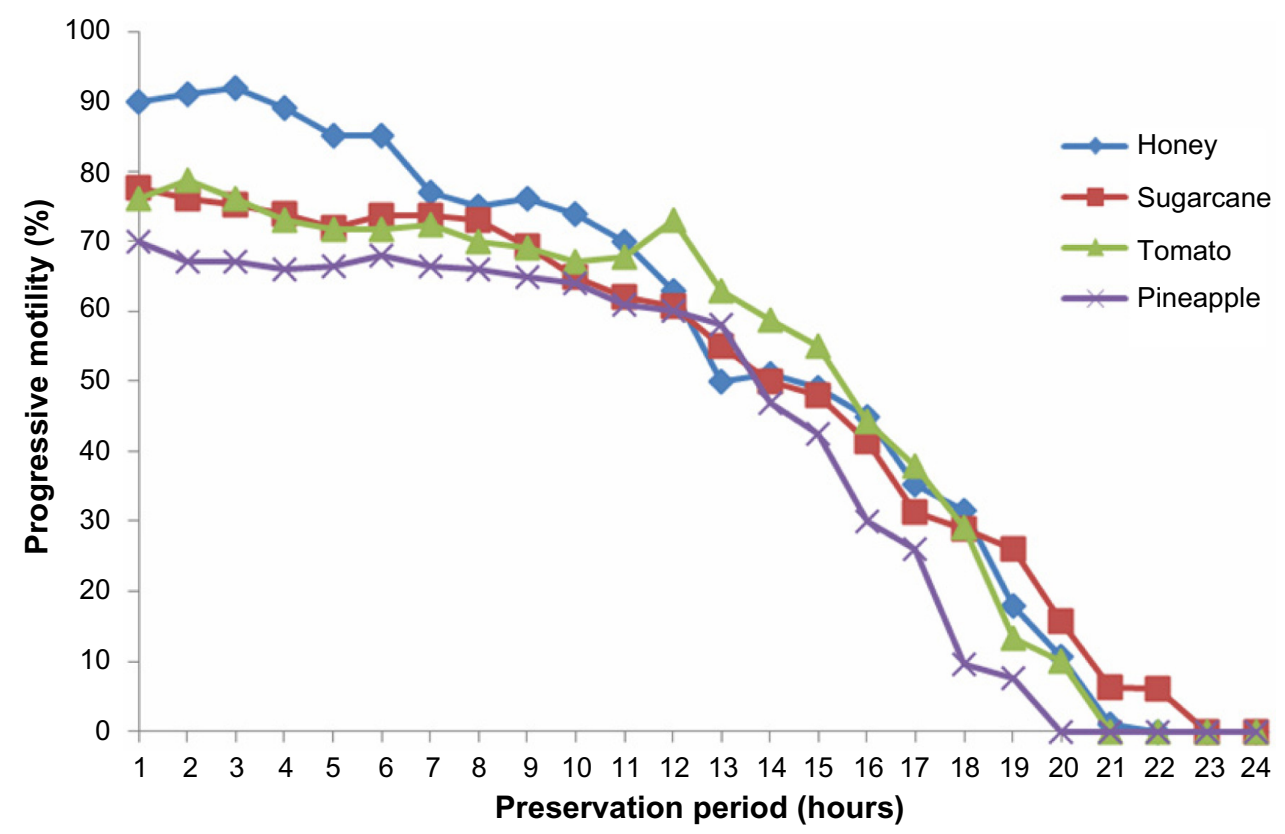

Figure 3 Survivability of spermatozoa based on motility assessment in the different extenders over time. 
the deterioration and damage to tissues, resulting in decline in motility and/or loss in fertility. ${ }^{31}$

\section{Conclusion}

Based on our findings, survivability of boar sperm stored under room temperature can be maintained longer in honey and sugarcane juice extenders compared with tomato and pineapple extenders. Although we did not compare the extenders to the most commonly used commercial extenders, the average achieved sperm survivability of about $60 \%$ in honey and sugarcane extenders may be efficient when used in boar AI programs, as morphology and acrosome integrity of sperm stored in these products show good conformation. This still needs to be examined before a conclusive statement can be made of the suitability of these extenders for boar AI. However, this study has shown that these natural products hold great prospect in our quest to develop local extenders that are of low cost, devoid of antibiotics, and environmentally friendly, using naturally available products for application in rural communities in many developing countries, where commercially known extenders are not readily available to swine farmers for AI.

\section{Author contributions}

SOU and AA conceptualized the study. All authors contributed to the design, analysis, and interpretation of the data. Also all authors contributed equally to the writing of the manuscript and agreed on the final draft.

\section{Disclosure}

The authors report no conflicts of interest in this work.

\section{References}

1. Gadea J. Review: semen extender used in the artificial insemination of swine. Spanish J Agric Res. 2003;1:17-27.

2. Johnson LA, Weitze KF, Fisher P, Maxwell WM. Storage of boar semen. Anim Reprod Sci. 2000;62(1-3):143-172.

3. Pursel VG, Johnson LA. Freezing of boar spermatozoa: fertilizing capacity with concentrated semen and a new thawing procedure. J Anim Sci. 1975;40(1):99-102.

4. Vyt P, Maes D, Dejonckheere E, Castryck F, Van Soom A. Comparative study on five different commercial extenders for boar semen. Reprod Domest Anim. 2004;39(1):8-12.

5. Sa S, Kim I, Choi S, et al. Effects of storage in different commercial semen extenders on sperm motility, viability and membrane integrity of Korean native boar spermatozoa. J Embry Transf. 2013;28(4):349-353.

6. van den Berg BM, Reesink J, Reesink W. TRIXcell+, a new long-term boar semen extender containing whey protein with higher preservation capacity and litter size. Open Vet J. 2014;4(1):20-25.

7. Kuster CE, Althouse GC. The fecundity of porcine semen stored for 2 to 6 days in Androhep and X-CELL extenders. Theriogenology. 1999;52(3):365-376.
8. Althouse GC, Lu KG. Bacteriospermia in extended porcine semen. Theriogenology. 2005;63(2):573-584.

9. Okazaki T, Mihara T, Fujita Y, Yoshida S, Teshima H, Shimada M. Polymyxin B neutralizes bacteria-released endotoxin and improves the quality of boar sperm during liquid storage and cryopreservation. Theriogenology. 2010;74(9):1691-1700.

10. Rozkot M, Frydrychová S, Beneŝová N, Opletal L. Small molecules of natural origin as a source of antimicrobial agents in pig breeding review. Res Pig Breed. 2013;7(2):26-33.

11. Tedeschi E, Menegazzi M, Yao Y, Suzuki H, Förstermann U, Kleinert H. Green tea inhibits human inducible nitric-oxide synthase expression by down-regulating signal transducer and activator of transcription-1alpha activation. Mol Pharmacol. 2004;65(1):111-120.

12. Mangiagalli MG, Marelli SP, Cavalchini G. Effect of lycopene on fowl sperm characteristics during in vitro storage. Arch Geflügelk. 2007; 71(1):S.25-S.29.

13. Wittayarat M, Ito A, Kimura T, et al. Effects of green tea polyphenol on the quality of canine semen after long-term storage at $5^{\circ} \mathrm{C}$. Reprod Biol. 2013;13(3):251-254.

14. Al-Daraji HJ. Effect of diluent supplementation with different levels of green tea on roosters' semen quality during in vitro storage. Int J Plant Anim Environ Sci. 2011;1(3):51-56.

15. Weitze KF. The use of long-term extender in pig AI - a view of the international situation. Pig News Inf. 1990;11:23-26.

16. Haugan T, Gaustad AH, Reksen O, Gröhn YT, Hofmo PO. Fertility results of artificial inseminations performed with liquid boar semen stored in X-cell vs BTS extender. Reprod Domest Anim. 2007;42(1): 94-99.

17. Ugwu SOC, Igboeli G. Motility and fertilizing capacity of boar semen stored in raffia palm (Raffia hookeri) sap extender at $15^{\circ} \mathrm{C}$. Afr J Biotech. 2009;8(9):1984-1987.

18. L Lustyková A, Frydrychová S, Lipenský J, Cerovský J, Rozkot M. Effects of long-term commercial extenders for liquid storage of boar semen. Res Pig Breed. 2010;4(2):9-12.

19. Ugwu SOC, Omeje SSI. Testicular development and relationship with sperm output in three genotypes of boars. Adv Appl Genet. 1995:10-18.

20. Elile FC, Ogbu CC, Ugwu SOC, Machebe NS. Libido and ejaculate characteristics of boars exposed to direct solar radiation. J Anim Plant Sci. 2014;24(1):43-49.

21. Machebe NS, Ugwu SOC, Ezume NE. Differential dietary energy effects on semen characteristics of indigenous turkeys reared in a humid tropical environment. Indian J Anim Res. 2012;46(4):341-347.

22. Cooper RA, Halas E, Molan PC. The efficacy of honey in inhibiting strains of Pseudomonas aeruginosa from infected burns. J Burn Care Rehabil. 2002;23(6):366-370.

23. Kwakman PH, te Velde AA, de Boer L, Speijer D, VandenbrouckeGrauls CM, Zaat SA. How honey kills bacteria. FASEB J. 2010;24(7): 2576-2582.

24. Pérez R. Feeding pigs in the tropics. FAO animal production and health paper 132 [webpage on the Internet]. Rome: Food and Agriculture Organization of the United Nations; 1997. Available from: http://www. fao.org/docrep/003/w3647e/w3647e00.HTM. Accessed December 4, 2013.

25. Pallavi R, Elakkiya S, Tennety SSR, Suganya Devi P. Anthocyanin analysis and its anticancer property from sugarcane (Saccharum Officinarum) peel. Int J Res Pharm Chem. 2010;2(2):338-345.

26. Vyt P. Examination and Storage of Liquid Porcine Semen [dissertation]. Ghent: Ghent University; 2007:77-92.

27. Frydrychová S, Čeřovský J, Lustyková A, Rozkot M. Effects of longterm liquid commercial semen extender and storage time on the membrane quality of boar semen. Czech J Anim Sci. 2010;55(4):160-166.

28. Aitken RJ, Buckingham DW, West K, Brindle J. On the use of paramagnetic beads and ferrofluids to assess and eliminate the leukocytic contribution to oxygen radical generation by human sperm suspensions. Am J Reprod Immunol. 1996;35(6):541-551.

29. Douard W, Hermier D, Magistrini M, Labbé C, Blesbois E. Impact of changes in composition of storage medium on lipid content and quality of turkey spermatozoa. Theriogenology. 2004;61(1):1-13. 
30. Surai PF, Karadas F, Pappas AC, Villaverde C, Sparks NHC. Organic Selenium In The Quail Diet Increases Se Concentration In Egg Shell. Proceedings XXII World's Poultry Congress, Istanbul, Turkey, June 8-13, 2004. World's Poult Sci Assoc. 2004. Page 595.
31. Cerolini S, Maldjian A, Surai P, Noble R. Viability, susceptibility to peroxidation and fatty acid composition of boar semen during liquid storage. Anim Reprod Sci. 2000;58(1-2):99-111.

\section{Publish your work in this journal}

Open Access Animal Physiology is an international, peer-reviewed, open access journal publishing original research, reports, reviews and commentaries on all areas of animal physiology. The manuscript management system is completely online and includes a very quick and fair peer-review system. Visit http://www.dovepress.com/ testimonials.php to read real quotes from published authors. 